\title{
Desejo na biopolítica do agora: performatividades escalares em um aplicativo de encontros homoafetivos ${ }^{1}$ Desire in the biopolitics of the now: scalar performativities in a homoaffective dating app
}

\author{
Luiz Paulo da Moita Lopes² \\ “A arte de viver [deve ser] contrária a todas as \\ formas de fascismo..." \\ Michel Foucault (1983 [1972]: xiii)
}

\section{RESUMO}

Com base na biopolitica do agora - um processo que envolve tanto a reocidentalização do mundo como a estabilidade dinâmica contemporânea - e em uma ideologia linguística performativa, este artigo relata uma etnografia da mobilidade em um aplicativo para encontros homoafetivos. Analisam-se performatividades escalares interseccionais de gênero, sexualidade e raça. São usados também os construtos teórico-analiticos de indexicalidade e escalas, que operam na compreensão de como os corpos são semiotizados no aplicativo. São focalizadas duas entrevistas

1. Sou grato ao CNPq pela bolsa de produtividade em pesquisa (CNPq 302935/2017-7) que possibilitou a investigação relatada neste artigo. Sou também agradecido à(o) parecerista anônimo(a) pela cuidadosa e exímia leitura do texto.

2. Professor Titular do Programa Interdisciplinar de Linguística Aplicada da UFRJ. Universidade Federal do Rio de Janeiro. Rio de Janeiro - Brasil. https://orcid. org/0000-0002-3829-9824. E-mail: moitalopes1@gmail.com.

3. Todas as traduções referidas em língua estrangeira são de minha autoria.

This content is licensed under a Creative Commons Attribution License, which permits unrestricted use and distribution, provided the original author and source are credited.

D.E.L.T.A., 36-3, 2020 (1-37): 2020360306 
etnográficas com dois participantes. Apesar da miríade de corpos e desejos semiotizados em uma dimensão acelerada, a matriz de inteligibilidade para os corpos de homens homoeróticos racializados em operação chama atenção para dois processos de projeções escalares. Esses remetem à reocidentalização do mundo tanto em relação a performatividades de masculinidade hegemônica como a performatividades racistas antinegros. Evoco a necessidade de pensar uma futuridade alternativa política radical em conjunto com uma visão crítica da biopolítica do agora.

Palavras-chave: performatividades; escalas; indexicalidade; interseccionalidade; biopolítica.

\section{ABSTRACT}

Considering the biopolitics of the now - a process that includes both the re-occidentalization of the world and contemporary dynamic stability-and a performative linguistic ideology, the article reports on an ethnography of mobility in a homoaffective dating app. It does so by analysing interseccional scalar performativities of gender, sexuality and race. The theoretical-analytic constructs of indexicality and scale are also relied on to illuminate how bodies are semiotized in the app. Two ethnographic interviews with two participants are focused on. Despite the myriad bodies and desires semiotized in an accelerated dimension, the intelligibilty matrix for racialized homoerotic male bodies in operation draws attention to two scale projections which speak to the re-occidentalization of the world both in relation to hegemonic masculinity performativities and to anti-black racist performativities. The article ends by evoking an alternative radical political futurity in conjunction with a critical view of the biopolitics of the now.

Keywords: performativity; scales; indexicality; interseccionality; biopolitics.

\section{Reocidentalização e estabilidade dinâmica: a biopolítica do agora}

Releio minha pesquisa dos anos 90 (Moita Lopes, 1998; 2002; 2006) sobre construções identitárias na escola. São fotografias amareladas de um mundo que, em muitos sentidos, não existe mais. Nossas vidas sociais interseccionalizadas ${ }^{4}$ em amálgamas de gênero, sexua-

4. A noção de interseccionalidade foi introduzida por Crenshaw (1989) ao defender a necessidade de um feminismo negro. Vou voltar à essa noção, posteriormente. 
lidade, raça, classe social etc., assim como a interação como lugar de sua construção, estão na foto. Focalizava, entre outras fabricações identitárias, a branquitude, a heterossexualidade, a masculinidade, como invenções semióticas universalizadas e suas materialidades corpóreas não-marcadas ou naturalizadas, de uma perspectiva socioconstrucionista. Essas construções operavam com base na racialização, sexualização e generificação da alteridade (negritude, homossexualidade e feminilidade). A pesquisa etnográfica ressaltava, entre outros fatores, como um mesmo jovem se alinhava interacionalmente a significados que o colocavam, nas práticas discursivas escolares como homem, heterossexual e branco na parte privilegiada de um mundo binarizado, como se fosse natural que as coisas fossem assim. Estávamos diante de um panorama inspirador para as ações político-ativistas dos importantes movimentos sociais que continuam a lutar para demolir esse "lugar de vantagem" socialmente injusto da branquitude, da heterossexualidade e da masculinidade: três invenções do mundo moderno-colonial que persistentemente continuam a destruir muitas formas de vida em uma tanatopolítica delirante (Agamben, 2002[1995]).

Mas a tecnologia que orientava o que ali se discutia nos eventos de letramentos estudados estava impressa no papel escrito. A sensação que se tem ao mirar essas fotos agora, por assim dizer, é que a vida pulsava vagarosamente nos anos 90 . Hoje é impossível imaginar nossas vidas sociais sem pensá-las onlineOffline ao mesmo tempo, em grande parte do planeta. Mesmo a maioria das práticas sociais offline não existem independentemente daquelas online. Para muitas pessoas, a vida tem lugar em conjunto com a tela de um celular, pelo menos. Quem pensaria, em tempos relativamente recentes, que poderíamos encontrar parceiros/as sexuais por meio de aplicativos de encontros afetivo-sexuais (Pelúcio, 2015; Bonfante, 2016); viver vidas multisituadas na escola, nas lanhouses, e no Facebook, nos quais sensualidade e raça se interseccionam (Guimarães, 2014 ; Moita-Lopes et al., 2019); ou ter relações sexuais por meio de telas de máquinas computacionais acopladas a sensores, em um mundo pós-humano (Martins, 2020) etc.?

A Modernidade, esse longo processo de ocidentalização do mundo (ou de levar o que terminou se constituindo como Europa para o resto do planeta), é entendida em geral por ter tido início no século XVI com as grandes navegações (Venn, 2000). Tem continuidade no 
que Mignolo (2020) chama agora de uma disputa contemporânea pela reocidentalização desse mesmo mundo, levada a efeito pela União Europeia e Estados Unidos em contenda com a China nos dias de hoje. Ainda que a Modernidade Colonial tenha suas peculiaridades, por exemplo, salvar as "almas" por meio de aceitação de um Deus cristão ao passo que escravizava e matava negros e indígenas e destruía suas cosmologias, é possível dizer que o processo contemporâneo de reocidentalização continua a desenvolver seus ideais de capturar para conquistar, colonizar, controlar, civilizar, destruir formas de vida existentes e, em última análise, ampliar o capitalismo excessivamente por meio de outros dispositivos contemporâneos como a tecnologia digital (Agamben, 2014 [2006]) .

Rosa (2019[2005]) avança a ideia de que a característica principal do que chamamos de Modernidade só se estabiliza no movimento: uma dinamicidade baseada em acumulação material, inovação nas práticas sociais e aceleração do tempo, sendo isso o que a estrutura e reproduz. Como o autor indica, essa dimensão processual evita as explicações da crítica pós-colonial, que prefiro chamar de decolonial ${ }^{6}$, expostas no parágrafo anterior. O sociólogo entende que, embora essas explanações façam todo o sentido e sejam irretorquíveis, não conseguem mais elucidar o movimento que subjaz às várias modernidades, uma vez que se apegaram a um argumento que se vincula a um período da história.

Para dar conta da noção de estabilidade dinâmica (um oxímoro perfeito!), Rosa (2019 [2005], p. xiii) lista três aspectos que fundam a Modernidade: "a economia de mercado capitalista-concorrencial, a democracia política, o regime de estado social, mas também os sistemas de ciência e educacional". A base desse processo todo é o crescimento

5. Como diz Agamben (2014 [2006], p. 37]), "o termo dispositivo nomeia aquilo em que e por meio do qual se realiza uma pura atividade de governo sem nenhum fundamento no ser. Por isso os dispositivos devem sempre implicar um processo de subjetivação, isto é, devem produzir o seu sujeito", como argumentarei logo a seguir.

6. O termo pós-colonial pode indicar que a colonização e seus efeitos acabaram, como critica Hall ( 2003), e ficou muito restrito ao mundo acadêmico anglofônico, deixando a América Latina fora do alcance do poder colonial (Bernardino-Costa e Grosfoguel, 2016). Decolonial enfatiza a necessidade contínua de empreender a transformação do próprio conceito "de Modernidade com o objetivo de vê-la como uma construção europeia da história a favor dos interesses da Europa" de modo a ser possível "imaginar e construir mundos futuros possíveis" (Mignolo, 2007 [2005], p. 24). Essa posição evita universalismos e inclui a necessidade do trabalho decolonial na América Latina.. 
infinito. O mundo precisa continuamente se desenvolver por meio de concorrência e de acumulação de capital. Se há um impeditivo a tal crescimento, somos levados à crise que vivenciamos hoje no Brasil ${ }^{7}$ e em outras partes do mundo. Essa obrigação de ampliação, rapidez e transformação é o que provê a estabilidade dinâmica, provocando a velocidade e aumento do consumo material, do uso dos computadores e da propagação de notícias: uma lógica que deve ser continuamente repetida na direção de sempre gerar expansão.

A Modernidade Recente tem agora o dispositivo da tecnologia digital e algorítmica (Tufecki, 2015; Maly, 2015) a seu dispor para dar efeito a processos de subjetivação, como resultado da reocidentalização em um mundo no qual tudo ainda é, mais especialmente, marcado por um capitalismo voraz e rápido. Os computadores intensificam essa mobilidade ao "adivinharem" nossos interesses, gostos e vontades, influenciarem nossas escolhas políticas e atenderem aos nossos desejos sexuais, em um mundo que opera com uma nova governamentalidade neoliberal ${ }^{8}$ ou com uma nova racionalidade (Brown, 2016; 2019).

Estar em ritmo de produção e avaliação contínuas é o que rege as vidas de muitas pessoas. A lógica do capitalismo neoliberal foi internalizada em nosso viver. Desse modo, a estabilização da vida social é sempre móvel, "se traduzindo para o âmbito da condução subjetiva da vida por via da competição por atribuições: não apenas de bens e recursos, mas também de privilégios e posições, de status e reconhecimento, de amizades e parceiros amorosos" (Rosa, 2019 [2005], p. xxi).

Uma vez que compreendo que a força motora do capitalismo subjaz tanto à lógica da ocidentalização do mundo (muito mais lenta!) assim como àquela operada pela visão de estabilidade dinâmica, catapultada das décadas finais do século XX até agora, penso que seja enriquecedor associar uma compreensão à outra. Assim, a lógica da reocidentalização continua atuante nas formas contemporâneas de colonizar e alienar

7. Penso que estados colonizados ou recolonizados, como o Brasil, vivem sempre em crise tendo em vista os acordos entre as elites locais e os colonizadores ou recolonizadores capitalistas.

8. Essa nova governamentalidade é orientada por políticas de desregulamentação dos mercados, de austeridade fiscal, de aplicação de impostos de formas injustamente uniformes, de destruição de garantias sociais para o trabalhador etc. (Brown, 2016), levando no Brasil, em tempos pandêmicos atuais, ao aumento do sofrimento das populações negras e pobres, em uma tanatopolítica devastadora. 
os corpos dos negros, das populações $\mathrm{LGBTIQ}^{9}+$, das mulheres, de certas nacionalidades, dos imigrantes, dos pobres, de certas religiões etc. em suas interseccionalidades, presentes na estabilidade dinâmica de nossos tempos. Ainda que essa força de dinamicidade não esteja disponível para todos - muitos continuam à parte dela em vidas estáticas marcadas por uma assimetria social escorchante -, cabe considerar o barateamento dos dispositivos digitais, principalmente na forma do celular, em um mundo no qual o ser humano passa a ser uma extensão de máquinas como o celular.

Neste artigo, utilizo o pano de fundo da reocidentalização e da estabilidade dinâmica, como propulsores da "historicização da biopolítica ${ }^{10}$ do agora" (Puar, 2007, p. xix ) para emoldurar a investigação das performatividades escalares (Nakassis, 2016) de raça, gênero e sexualidade em um aplicativo para encontros homoafetivos, típicos da rapidez de nosso capitalismo neoliberal exacerbado atual. A busca por parceria afetivo-sexual em aplicativos é um exemplo da estabilidade dinâmica da lógica do capitalismo contemporâneo que passou a mobilizar nossas subjetividades de forma diferente em tempos relativamente recentes. A estabilidade dos encontros se dá de forma intensamente móvel por meio de escolhas contínuas e frenéticas de parceria afetivo-sexual, o que envolve a formação das comunidades 'leves' e efêmeras das redes sociais em oposição a comunidades 'espessas' como família, nação etc., que incluem copresença física (Blommaert \& Varis, 2015). Tais escolhas são orientadas por processos de generificação, sexualização e racialização, entre outros, no aplicativo, que com base na biopolítica do agora epistemologicamente constroem pactos inventados sobre "ontologias" inferiores e superiores (Mignolo, 2020). Como biopolítica, esses processos sustentados nos aplicativos são virais (Gallo, 2016). Daí também a relevância de serem estudados.

9. Lésbicas, gays, bissexuais, trans, intersexuais, queer e outras, ou seja, sexualidades que questionam a "matriz da heterossexualidade" (Butler, 1990, p. 156) à qual estamos todos submetidos.

10. Foucault (1999 [1997], pp. 292-293) aponta que a biopolítica nasce no século XVIII e XIX para focalizar não mais o indivíduo e seu corpo (como fazia na sociedade disciplinar ao substituir a ordem do soberano) mas a população: "a biopolítica lida com a população, e a população como problema politico, como problema a um só tempo científico e politico, como problema biológico e como problema de poder." 
Na seção seguinte, discuto a etnografia digital levada a efeito na investigação relatada ao passo que descrevo os espaçosTempos e as práticas discursivas que orientam as performances no aplicativo e sua natureza de estabilidade dinâmica. A seguir, apresento uma visão performativa da linguagem e das vidas sociais como efeitos performativos escalares interseccionais de gênero, sexualidade e raça. Descrevo a natureza semiótica escalar dessas performatividades com base em como são indexicalizadas. A seguir, passo a análise de duas entrevistas etnográficas com dois participantes (um semiotizado como branco e outro como negro) de uma comunidade em um aplicativo de encontros homoafetivos. Ao concluir, chamo atenção para a persistência da reocidentalização do mundo, coexistindo na biopolítica do agora, assim como para a importância de ter em mente uma outra futuridade.

\section{Etnografia da mobilidade em aplicativos de encontros homoafetivos}

Com a vida sendo vivida cada vez mais de forma onlineOffline, estudos de etnografia virtual e multisituados onlineOffline (Guimarães, 2014; Camargo, 2019) passaram a ser essenciais. Tais etnografias, também chamadas de etnografias online, netnografias e webnografias (Hine, 2015; Kozinets, 2010), são crescentemente de interesse da pesquisa contemporânea no campo de estudos aplicados da linguagem (e em outros). Blommaert (2007) constrói uma metodologia que chama de etnografia da mobilidade ou do texto. Tal metodologia parece fornecer um modo de entender etnograficamente os processos de construção de significado nos espaços digitais fluidos, focalizados nesta pesquisa: conversas escritas (e também multimodais) no WhatsApp e em aplicativos para encontros homoafetivos. O autor indica que tal metodologia possibilita "compreender o que acontece quando as pessoas performam aquele modo mais elementar de comportamento social humano, a comunicação, em padrões de mobilidade humana e semiótica que agora definem nossas sociedades" (Blommaert, 2007, p. 32).

Ele nos convida a proceder a tal estudo "com detalhes etnográficos reais" (p. 32), apresentados nessa seção, que explicam o fluir dos textos e das pessoas. Blommaert (2007, p. 18) chama atenção para o fato de 
que a etnografia não pode ser reduzida ao trabalho de campo como resultado da aplicação de técnicas e métodos. Pensa ser necessário uma visão teórica do uso da linguagem e das pessoas em performance bem como "uma posição epistemológica e metodológica" (p. 18). Dessa perspectiva, ele enfatiza a natureza situada e contextualizada de nossas ações, o entendimento interpretativista dessas ações, assim como a compreensão de que detalhes microanalíticos se friccionam com discursos disponíveis para os participantes na construção do significado.

O autor acrescenta ainda que os textos carregam traços de significados de outras práticas para aquelas nas quais são recontextualizados ou reentextualizados em sua circulação na mobilidade de nossas vidas. Essa recontextualização vai possibilitar a recuperação dos processos de indexicalização e escalares projetados pelos participantes, como discutirei posteriormente. Dou início a essa recontexualização de textos (como combinações de signos) a partir de agora para começar a descrever os "jogos de linguagem" (Wittgenstein, 1968 [1953], p. 184) e os contextos de uso nos aplicativos baixados em celulares.

Não esqueço o dia em que um amigo abriu o celular e disse para minha surpresa: "está vendo, esses são os caras disponíveis para encontros nessa área". A tela do celular em cima da mesa de um bar mostrava dezenas de fotos dos participantes. Para ser acolhido na comunidade do aplicativo, o participante tem que inscrever seu perfil e ser aceito pelo moderador ${ }^{11}$. Da mesma forma, o pesquisador precisa construir um perfil e se submeter às regras de uso do aplicativo como fornecer e-mail e outros dados pessoais. Trata-se de construir uma visão êmica pela própria natureza da regulamentação do uso do aplicativo de modo a entender o que está acontecendo sem estar escondido mas como um participante qualquer, agindo sincronicamente. A tentativa é de falar em conjunto com os participantes e não por eles.

Aplicativos de encontros sexuais e/ou amorosos se tornaram parte constitutiva das práticas sociais contemporâneas em vários lugares do mundo. Entre os jovens (e outros não-jovens também!), deve ser difícil encontrar quem não tenha feito uso desse modo de conhecer parceria

11. O moderador é um sistema de comandos, que filtra eletronicamente se a foto de seu perfil apresenta partes do corpo nu, se o usuário do aplicativo aceitou as normas de participação, os participantes que você deseja encontrar etc. 
afetiva ou sexual. Casamentos e namoros, independentemente do tipo de objeto de desejo construído, são agora muito comuns via aplicativos - veja Pelúcio (2015) sobre o uso de aplicativos para encontros heteroafetivos. Pode-se então conversar, trocar fotos e marcar um encontro por meio do aplicativo. É comum que os participantes troquem o número de WhatsApp para conversas mais longas e enviem mais fotos se estreitarem mais os laços. Cada participante tem seu perfil com foto, que pode ser do rosto ou de qualquer outra coisa (uma foto sem a cabeça, por exemplo), mas que não mostre partes íntimas. O participante pode também escolher não incluir nenhuma foto. $\mathrm{O}$ uso inadequado de fotos pode resultar em não aceitação pelo moderador. Os participantes são aconselhados a incluírem uma foto do rosto uma vez que essa desperta mais interesse, ou provavelmente porque já provoca o início da seleção mais rápida do parceiro. Os participantes estão sempre sujeitos a serem denunciados se as regras não são cumpridas.

Além disso, o participante é convidado a adotar um nome ou apelido (EncontroJÁ ${ }^{12}, 22 \mathrm{CM}$, DIVERSÃO, João Grandão, por exemplo), a permitir que apareça junto à foto a distância que um participante está de um outro, a indicar o que procura (conversa, amigo, encontro, agora, relacionamento etc.), a mostrar a idade ou não. A seguir, o participante pode continuar se semiotizando ao marcar uma série de categorias ${ }^{13}$ que definem altura, etnia (asiático, branco, indígena, latino, mestiço, negro, outro), porte físico (comum, grande, magro etc.), posição no ato sexual (ativo, versátil ativo, passivo, versátil passivo etc. ${ }^{14}$ ), tribos (urso, i.e. homem peludo; elegante, papai, i.e. maduro a procura de parceiros mais jovens ou o contrário; couro (participante que usa vestimentas de couro para atividades sexuais); nerd; barbie, i.e. participante musculoso; soropositivo; trans; relacionamento atual (casado, com parceiro, comprometido, relacionamento aberto, solteiro etc.), local de encontro

12. Nas redes sociais, letras maiúsculas são usadas para efeitos de ênfase.

13. Como vou argumentar depois, essas categorias são um convite ao participante a projetar escalas semióticas sobre "quem é" de modo que seja mais facilmente encontrado por quem o procura. Começa assim a performatização de uma "ontologia" por meio desse processo de semiotização.

14. Esta é uma compreensão muito tradicional dos atos sexuais, mas que parece ser muito importante para os participantes. São raros aqueles que não incluem tal posição em seus perfis. Muito comumente adotam a posição como seu nome (por exemplo, ATV ou $22 \mathrm{CM}$, i.e. o tamanho do pênis). Tais signos exemplificados indexam os mesmos tipos de significados sobre a posição sexual. 
(minha casa, bar etc.), desejo de receber fotos sem roupa ${ }^{15}$ (nunca, sim por favor etc.), gênero (homem cis, homem trans etc.), não conformista (não binário, travesti etc.), escolha de pronomes de referência (ele, pronome personalizado por usuário trans etc.), saúde sexual (status HIV, data do último exame, possibilidade de agendar quando deve fazer o próximo exame, perguntas e respostas sobre saúde sexual); rede social (para acrescentar o endereço do Instagram, por exemplo).

Em uma outra parte, o participante pode escrever outras preferências ou salientar escolhas de modo mais aberto como "maduros passam na frente da fila", "não faço uso de drogas", "English, Español”, "gosto de afeminados", "casado com mulher", "somente caras até 40 anos", "procuro travestis" ou "adoro cinema". É notável também a existência de um help center bem informativo, em várias línguas, que esclarece a importância da identificação de algumas categorias (por exemplo, é ofensivo se referir a um homem cis como ela?) ou informações sobre como se comportar (por exemplo, transfobia é explicitamente proibida aos participantes, que podem ser denunciados).

A escolha de perfis mesmo para quem não é um usuário pagante, como foi o meu caso, é bem grande: cerca de 110 pessoas num raio de poucos metros ou poucos quilômetros de distância de onde o seu celular estiver, podendo fazer três filtragens básicas na procura (coroas, garotos, couro, por exemplo). Já os pagantes podem filtrar muito mais suas procuras e têm a possibilidade de alcançar 600 perfis no aplicativo. Está clara, portanto, a interferência da estabilidade dinâmica do capitalismo contemporâneo na subjetividade das pessoas, como já chamei atenção anteriormente. A mobilidade expressa na variabilidade de parceria afetivo-sexual em potencial e a velocidade com que essa pode ser encontrada é característica dos aplicativos. O participante pode escolher ter quantos encontros quiser durante 24 horas, por assim dizer, ou fazer uma programação para a semana. E isso não quer dizer que os encontros vão se transformar em encontros sexuais nem em casamentos. Essa característica não implica, por outro lado, que esses tipos de aplicativos não sejam também usados por profissionais do sexo. Nesse caso, os participantes já deixam seus propósitos claros

15. Nas conversas entre os participantes, qualquer tipo de foto pode ser enviada, sendo de fato tais trocas de fotos muito solicitadas. 
antes do encontro: "massagista", "só trabalho", "profissional", GP (i.e. garoto de programa), por exemplo.

Por meio de toques nas telas do aplicativo, se escolhe quem se deseja, responde-se a quem te escolhe, imediatamente se enceta uma conversa e se pode partir para um encontro imediato subsequente ou para quando se desejar ou nunca (essa mesma dinâmica é verificada em aplicativos heteroafetivos - Pelúcio, 2015). A velocidade que caracteriza viver essas práticas discursivas pode ser inicialmente assustadora para pessoas não socializadas nelas já que a intimidade da vida sexual pode estar disponível para todos os participantes. Ademais, o aplicativo também se move com o corpo do participante, em um mundo no qual o celular é sua extensão. Tal característica possibilita acesso a parcerias afetivo-sexuais translocais onde quer que se esteja (em outros bairros, cidades, países e continentes): um movimento que exige relocalização do participante. Esse é um outro exemplo que enfatiza a estabilidade dinâmica.

Usei o aplicativo como participante, para realizar a etnografia por cerca de 10 meses na zona sul do Rio de Janeiro, no bairro de Copacabana. Embora a zona sul do Rio seja normalmente compreendida como habitada por classes sociais mais afluentes, isso não é necessariamente assim. Esse bairro é caracterizado por conter uma mistura social da cidade e ser densamente povoado. Além de uma grande população turística flutuante nacional e internacional, há também moradores de um amplo leque social: habitantes de um sem-número de apartamentos pequenos conhecidos como kitchnetes, das comunidades dos morros (como um dos participantes que entrevistei), de outros bairros que vêm a Copacabana (o caso de outro participante entrevistado) para trabalhar no grande setor de serviços (hotéis, shopping-centers, lojas, restaurantes etc.) ou desfrutar da praia. Esses convivem no bairro com moradores de classes sociais médias e mais altas. Talvez seja possível dizer que a cidade do Rio de Janeiro (ou mesmo o mundo) passa por Copacabana todo dia, por assim dizer. Por conseguinte, o mesmo pode ser dito em relação ao aplicativo em uso em Copacabana.

No meu perfil, coloquei a foto de uma estátua e um nome fictício como é comumente feito por muitos participantes. Descrevi "quem eu sou" com base em algumas das categorias gerais elencadas: altura, peso, idade etc. Não é necessário preencher todas e, de fato, nenhuma. 
Alguns participantes só enviam fotos com o rosto para aqueles por quem se interessam, o que pode ser feito diretamente quando enviam uma mensagem. Muitos outros, porém, divulgam fotos do rosto no perfil e uma grande maioria publica fotos usando sunga de praia sem rosto, para exporem seus corpos imediatamente. Além de darem início a uma conversa direta com o envio de mensagens, o participante pode visitar um perfil dando um 'oi!', o que implica algum interesse uma vez que é possível visitar perfis sem dizer nada. A quantidade de pessoas que visitam e enviam mensagens é bastante grande. Para os participantes pagantes, a mobilidade é frenética uma vez que, como já frisei, envolve 600 perfis em uma relocalização intensa a um só tempo.

Pelúcio (2015) discute as implicações éticas como também afetivas que o/a pesquisador(a) pode enfrentar no uso deste tipo de aplicativo. Assim, deixei claro de início meu propósito ("Sou pesquisador da UFRJ e estudo gênero, sexualidade e raça nesse aplicativo") quando fui conversar com algum participante para evitar qualquer tipo de vinculação, que não fosse estritamente relativa à pesquisa. Ignorei qualquer tipo de abordagem dos participantes. Por razões éticas, nenhum nome usado neste artigo é identificável assim como não descrevo nenhum perfil exatamente como aparece a não ser com informações esparsas sem identificação e nem uso datas assim como também não identifico o nome do aplicativo. As entrevistas foram realizadas por WhatsApp, tendo então os participantes acesso ao meu nome completo e foto com rosto. Abordei diretamente cinco participantes que marcavam sua raça como negra ou preferência por uma raça específica, porque me interessava justamente visibilizar as interseccionalidades de gênero, sexualidade e raça. Os cinco participantes escolhidos aceitaram meus convites para uma conversa imediatamente, e marcamos uma hora conveniente. Fiz entrevistas aprofundadas com esses cinco participantes. Meus diários de campo possibilitaram escrever esta seção sobre o que ali acontecia.

Com o passar do tempo, o participante se acostuma com os modos de participação no ethos da comunidade: ser escolhido ou selecionar um potencial parceiro, ser correspondido ou não, avaliar fotos recebidas, enviar fotos se assim desejar, verificar quem deu só um "oi!", replicar o "oi!" ou não, responder a outros participantes, manter contato fático ou desenvolver um bate-papo contínuo sem ter visto foto ou enviado foto. É notável também o fato de alguns participantes aparecerem com 
mais frequência no aplicativo por causa de sua localização geográfica enquanto outros nunca mais são vistos. Além disso, as características das restrições das categorias do perfil, os textos informacionais em várias línguas, a origem estadunidense do aplicativo e o alvo econômico e internacional projetado para os participantes tornam o uso de um transidioma (Jacquemet, 2005) comum. Assim, tanto nos textos do aplicativo (nerd, NSFW, i.e. aceito receber fotos de pessoas nuas de imediato, help desk, por exemplo, ao lado de outras palavras pouco usuais no português brasileiro como "cafeteria") como nos textos dos participantes, um tipo de portEnglish é habitual: "só job", "boy massagista", "somente barebacking", i.e. sexo sem uso de preservativo, por exemplo ${ }^{16}$. O participante atua no que pode ser chamado de uma comunidade 'leve', como já apontado, e GBTIQ+ globalizada. Uma tal comunidade pode ser também compreendida nos moldes do que referi anteriormente como típico da reocidentalização do mundo.

A categoria 'latino', oferecida como opção para semiotizar raça, por exemplo, não é usada no Brasil. Mas, nos Estados Unidos, identifica pessoas originárias da América Latina e implica que o participante é não-branco. Essa categoria, todavia, é raramente escolhida no Brasil pelos participantes, que se entendem em geral como negros, mestiços ou brancos. Um outro ponto dessa globalização é o help desk, já mencionado, que esclarece oportunamente como se comportar de modo adequado com outros participantes, onde ir em caso de DST, como fazer uso de PREP (utilização de retrovirais que evitam o contágio por HIV) etc., colaborando para disseminar informação de forma planetária e para construir uma comunidade translocalizada em relação ao que conta como letramento relevante para esse grupo de pessoas. Outras categorias (por exemplo, couro, urso, nerd, barbie etc.) acabaram viralizadas pelo mundo na construção de uma "cultura" GBTIQ+ internacionalizada, mas que tem base estadunidense e pode ser também compreendida como parte de um tipo de reocidentalização.

É verdade, porém, que há sempre a possibilidade de um ponto fora da curva no uso do aplicativo uma vez que há espaço para que os participantes especifiquem algo mais localizado de sua percepção em relação

16. Tais usos estão também alinhados à mobilidade contemporânea de pessoas, linguística e textual na Internet em nosso mundo onlineOffline (Pennycook, 2012, Moita Lopes, 2018, por exemplo). 
às suas práticas ou ao tipo de parceria que procuram ou outras questões mais situadas. São exemplos dessa localização reentextualizações feitas pelos participantes em seus perfis como "não tenho muito o que dizer aqui para impressionar vcs" 3 ; "nunca somos suficientemente 'bons'. No entanto, um belo dia chega alguém que satisfaz nossa insuficiência"; "um preto para outro preto"; "candomblecista e politicamente de esquerda"; "não estou atrás de sexo", "Bolsonaro não", "esse aplicativo é uma caixinha com meus desejos sexuais" e "sexo é escolha, amor é prêmio". Esses enunciados, de certa forma, quebram o ritmo rápido e translocal do aplicativo. Assim, o que é semiotizado no aplicativo pode ter as peculiaridades da vida local em performatividades identitárias hibridizadas translocalmente pelo próprio aplicativo.

Nenhuma categoria, no aplicativo, aponta diretamente a classe social embora essa possa ser identificada também por outras reentextualizações, por exemplo, relativas ao bairro da cidade em que o participante mora (o que pode ser descoberto na conversa ou pela identificação de distância), aos lugares que as fotografias mostram etc. Nesse sentido, é relevante avaliar a afirmação de Mignolo (2020) que salienta que a "Europa cheira à classe, mas as Américas à raça"17. O foco em raça tão explícito no aplicativo talvez tenha a ver com o fato de esse dispositivo ter sido criado nos Estados Unidos. Nesse país, assim como no Brasil, a problemática do racismo antinegros é muito flagrante e estrutural, como discutirei a seguir.

\section{Performatividades escalares interseccionais de gênero, raça e sexualidade}

Nas telas de computadores de vários tipos assim como nas de celulares, a mobilidade intensa contemporânea tem guiado muitos sociolinguistas na construção de ideologias linguísticas (Moita Lopes, 2018 e 2020) que expliquem essa dinamicidade acelerada. Para muitos é impossível pensar sobre linguagem atualmente sem considerar nossas vidas onlineOffline, como neste aplicativo, em termos de mobilidade:

17. "Classe é uma categoria da história européia, que se tornou evidente com a Revolução Industrial, mas raça é conseqüência da "Revolução Colonial" no século XVI" (Mignolo, 2005: s/p). 
a) transidiomática (Jacquemet, 2005; Moita Lopes, 2017) nos usos linguísticos que operam com pedaços de línguas diversas em sociedades e redes sociais que se caracterizam pela superdiversidade de línguas em uso etc. (Vertovec, 2007); b) textual nas várias trajetórias de reentextualizações contínuas e intensas nas redes sociais (Blommaert \& Rampton, 2012; Fabrício, 2018; Moita Lopes \& Fabrício, 2018a e b); e c) de recursos semióticos (Heller, 2010) inúmeros dos quais lançamos mão (signos linguísticos, fotográficos, videóticos etc.) na construção performativa dos significados. Uma ideologia linguística adequada à mobilidade intensa de nossos tempos se desloca de uma linguística internalista e referencialista do sistema para uma linguística externalista e conotacional de índices linguísticos (Blommaert e Rampton, 2012; Collins 2020 [2011]) assim como para uma linguística dos textos, como combinação de signos em movimento, que indexam significados performativamente (Blommaert \& Rampton, 2012; Fabricio e Moita Lopes, 2019).

A noção dos significados como sendo performativos advém do pensamento de Austin (1962), que chama atenção para como fazemos coisas no mundo com a linguagem. Os atos de fala são performativos uma vez que produzem o que descrevem nas ações sociais, provocando efeitos de sentidos. Portanto, acarretam a elaboração de uma ideologia linguística externalista dos efeitos pragmáticos dos atos nas práticas discursivas nas quais agimos. Tais atos e seu uso no mundo social envolvem o fenômeno ao qual Derrida (1988 [1972]) se referiu como iterabilidade, ou seja, repetição e diferença. Embora haja repetição no uso de atos de fala (por exemplo, quando um participante cumprimenta um outro escrevendo "Beleza?" ou "Tudo bem?", que são bastante comuns no uso do aplicativo - engendrando previsibilidade e sedimentação- , a repetição desse ato nunca é igual uma vez que o participante pode, por exemplo, usar BELEZA? (indicando volume alto da voz), acrescentar a esse cumprimento uma foto dele de nu frontal ou saudar o participante diretamente com tal foto sem dizer nenhuma palavra e ainda porque o efeito performativo depende da interpretação de outros. O significado nunca está totalmente determinado: a indecisão está em sua natureza.

Ao passo que esse ato de fala de saudação reitera o que se espera em um primeiro encontro, também evoca diferença uma vez que pro- 
voca efeitos pragmáticos inovadores. Tais efeitos diferentes podem englobar uma metapragmática alternativa para a saudação, isto é, a compreensão de que o participante está fazendo um convite explícito para um encontro sexual ou de que espera reciprocidade imediata de envio de uma fotografia da mesma natureza, por exemplo. Essa também é uma linguística conotacional uma vez que valoriza a variabilidade de sentidos que signos específicos podem ter no uso ao mobilizarem discursos específicos, como acabei de argumentar. A foto do participante nu pode evocar discursos diferentes ou mobilizar metapragmáticas alternativas. Prestigio uma linguística, que deseja chamar atenção para os discursos que os signos indexicalizam (Silverstein, 2003; Blommaert, 2005 ; 2010) nas ações discursivas performativamente, com base em repertórios de sentidos, ideologias e valores etc. dos quais os participantes lançam mão na interação. Operar analiticamente com base na indexicalização dos significados é realçar a natureza friccional entre os signos e os significados indexados, ou seja, é recusar a separação tradicional entre aspectos micro e macro do discurso.

Assim, a socialização dos participantes no uso deste aplicativo, por exemplo, envolve aprender a operar com os índices / signos e com os significados ou discursos, valores e ideologias para os quais aqueles apontam (Agha, 2007), o que Silverstein (2003) chamou de ordem indexical ${ }^{18}$. Muito dessa socialização, porém, pode acarretar a desambiguação de metapragmáticas possíveis das relações entre signo e seus efeitos performativos no ato de fala, como ressaltei em relação à foto de nu frontal. Outros signos são parte das práticas discursivas translocais como é o caso do índice ' $4: 20$ ', que tive que aprender em minha socialização, uma vez que indexa discursos que identificam participantes da cultura canabis internacionalmente, com os quais não estava familiarizado. Outros índices são mais típicos da cultura fetichista gay como XXL ou DOT (i.e. dotado), que apontam para significados sobre o tamanho do pênis.

Esses podem ser facilmente compreendidos como parte das economias masculinistas e patriarcais, que atuam com sentidos essencializados e universalizados sobre quem os homens são, em muitas lugares

18. Ou seja, uma ordem indexical se refere aos repertórios semânticos com base nos signos de várias naturezas dos quais dispomos. 
do globo, ainda que tenha visto um participante escrever na parte livre do seu perfil: "sou indiferente ao tamanho do seu pau". Como já frisei, signos e textos viajam translocalmente e, nessas recontextualizações, mobilizam outros sentidos. Outros signos usados no aplicativo são parte da "cultura" do uso de emojis, que são de conhecimento comum internacional de qualquer pessoa que frequenta as redes sociais. De fato, como apontam Blommaert e De Fina (2015), como efeitos da globalização, "recursos locais e globais constituem pacotes complexos de indexicalidade".

Atentar para os signos e os significados que indexicalizam para os participantes também possibilita efetuar uma abordagem sensível a projeções escalares no discurso (como faz Schultz, 2020) ou compreender como os participantes perspectivizam semioticamente o mundo ao seu redor, os outros e a si mesmos ao localizarem tempo-espacialmente, identificar, metrificar, qualificar, avaliar a si próprios, outras pessoas, coisas, ações etc. (Carr e Lempert, 2016). Essa é uma posição teóricoanalítica que se baseia na compreensão de que como seres dos discursos construímos e somos construídos performativamente no trabalho de semiotização da vida social, no qual estamos envolvidos, não havendo ontologias prefiguradas (Pinto, 2018) antes de tal semiotização. Somos e vivemos no mundo como efeitos dos significados que forjamos uns para os outros.

As categorias disponibilizadas para os participantes escolherem ao preencherem o seu perfil, por exemplo, como salientei na nota 13 anteriormente, são projeções escalares utilizadas para que, de imediato, se semiotizem e performatizem quem são escalarmente. Ao selecionarem ou não categorizações como raça, posição sexual, idade, gênero, escolha de tratamento pronominal etc., em conjunto com os textos que incluem no perfil, constroem performatividades escalares (Nakassis, 2016) sobre como se semiotizam ou desejam ser semiotizados, em relação ao gênero, sexualidade e raça, entre outras posicionalidades sociais. A projeção de tais performatividades escalares chama atenção para o trabalho semiótico vigoroso, no qual os participantes estão envolvidos o tempo todo, no processo de escolher um outro ou de ser escolhido. Essa é uma atividade que continua quando uma mensagem é enviada e lida. 
Seguindo Butler (1990) e uma série de teóricos queer ${ }^{19}$ (Sullivan, 2003; Ruti, 2017; por exemplo), entendo que o que somos emerge na interação, ou seja, não existe antes do discurso. Essa visada é importante por que coloca relevância nas práticas discursivas cujos efeitos performatizam sentidos sobre nossos corpos e desejos eróticos e, de fato, sobre sua materialidade ou corporalidade. Uma tal compreensão é importante por que baseada, entre outros, em Austin e Derrida, mencionados anteriormente, Butler desessencializa qualquer sentido biologizante e binário sobre nossos corpos. Os atos performativos de gênero e sexualidade terminam por descortinar o que deles é esperado sob regulamentações rígidas sancionadas socialmente sobre o que os nossos corpos podem fazer. Contudo, nas repetições dessas regulamentações, nossos corpos sempre podem escapar delas uma vez que a repetição nunca é igual. Os atos performativos de gênero e sexualidade chamam atenção para a sua natureza de ficção pactuada (Preciado, 2015) sobre quem somos.

Embora as questões de raça não tenham sido tratadas diretamente por Butler (1990), no prefácio da edição de 1999 desse livro, a autora chama atenção para os aproveitamentos que têm sido feitos sobre a teoria da performatividade pelo campo de estudos raciais. O ponto que ressalta é que se deve considerar o que acontece quando a teoria tenta incluir raça, enfatizando a importância de que essas categorias escalares que semiotizam os corpos sejam entendidas como uma transpassando a outra e não como uma sendo acoplada à outra. A sexualização de gênero e raça deve ser compreendida em conjunto ao passo que essa concepção aumenta a natureza instável dessas performatividades. Tal posição enfatiza a necessidade de as compreensões teórico-analíticas sobre performatividades escalares de gênero, sexualidade e raça terem que ser necessariamente interseccionalizadas, como já mencionado na nota 4.

Barnard (2004), em seu livro providencialmente intitulado Queer Race (Raça Queer), salienta que é impossível tratar de sexualidade sem

19. Em geral, essas teorias são compreendidas como advindas das teóricas feministas Butler (1990) e Sedgewick (1990). Entendem a sexualidade como não sendo estável, universal, transhistórica e transcultural (Jagose, 1996) e operam sob a necessidade de que essa precisa ser desnormalizada e desnaturalizada em seus binarismos tradicionais essencializados e homogeneizados como heterossexualidade e homossexualidade. 
incluir a questão racial. Barnard (2004, p. 108) aponta a necessidade de queerizar raça: “o 'queer' da teoria queer não pode ser entendido como existindo isoladamente, ou pelo menos não pode dar a entender que se refere à sexualidade somente". Ademais, na nossa Modernidade Colonial desatinada sobre a qual fala Mbembe (2014[2013]), os esteios da colonização continuam a definir a vida contemporânea em muitas partes do mundo, inclusive no Brasil, pela imaginação imposta que determinam as performatividades 'corretas' e 'puras' de raça, gênero e sexualidade com base em suas marcas 'biológicas', como se gênero, sexualidade e raça pudessem ser assim definidos. Essa imaginação colonizada e muito solidificada continua a atuar em benefício da "hegemonia política" dessas ditas performatividades "puras" (Raudio. 2001: 36), que precisam ser queerizadas ou desnaturalizadas.

O Brasil é um exemplo perfeito dessa Modernidade da Reocidentalização insistente a que já me referi. Vivemos em um sistema racista antinegros (e antiindígenas!), que por sua natureza estrutural, como diz Almeida (2019), constitui as relações sociais desse sistema como um padrão de normalidade do dia-a-dia tanto dos pontos de vistas político, econômico e subjetivo. Que os homens brancos e cis-heteros tenham as vantagens sociais que têm é parte da naturalização das práticas históricas de poder sob as quais vivemos. A máquina colonial, para seus benefícios capitalistas da conquista, cristalizou semioticamente como inferiores, as alteridades negras, indígenas, femininas e homossexuais sob o chicote daqueles que traziam a civilização e a metafísica de um Deus cristão. Essa máquina, como já frisei, continua em operação na disciplinarização (Foucault, 1987[1975]) e controle dos corpos (Deleuze, 1992[1990]) ou mesmo em sua tanatopolítica (Agamben, 2002[1995]), como apontarei ao concluir.

A semiotização de nossos corpos opera como efeitos de certos sentidos (e não outros) como projeções de performatividades escalares de gênero, sexualidade e raça, que emergem no discurso. Esse movimento escalar possibilita que os corpos performatizem efeitos de sentidos em uma determinada narrativa sobre quem são. Conforme já salientei, como efeitos de significados no jogo de repetição e diferença, tal semiotização é regulamentada socialmente, mas a repetição como cópia é sempre outra e é continuamente moldada de forma diferente. 


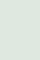

Há sempre desencaixes de modelos prefigurados em nossos contínuos devires interseccionais.

Na próxima seção, passo a analisar performatividades escalares nas intersecções de gênero, sexualidade e raça em duas entrevistas, geradas etnograficamente, com participantes do aplicativo de encontros homoafetivos. Foram entrevistados individualmente em uma conversa escrita informal pelo WhatsApp e selecionados por que projetavam performatividades escalares racializadas para seus corpos de homens gays negros e brancos e para seus desejos homoeróticos.

\section{A biopolítica do agora na projeção de performatividades escalares racializadas homoeróticas}

Tendo em vista o fato de que o aplicativo em análise convida à semiotização racial dos corpos, ou seja, à projeção de performatividades escalares raciais sobre os corpos de pessoas GBTIQ+ na biopolítica do agora, e o fato de que tais racializações são levadas a efeito para além das categorias dadas no aplicativo, construí como um "ponto rico"20 (Sandel, 2015) de análise das entrevistas/conversas etnográficas a compreensão das racializações homoeróticas nas reentextualizações de dois participantes.

Para este artigo, selecionei as entrevistas de Pedro e de Leandro para analisar suas performatividades escalares com base nas análises dos discursos reentextualizados. Começo com a análise da performatividade escalar de Pedro, que semiotiza a si mesmo e seu companheiro como homens-cis e brancos a procura de um terceiro parceiro. Pedro tem 40 anos e é morador de Copacabana. As marcas de edição da entrevista são identificadas com (...) e a identificação da continuação da escrita da mesma pessoa com :.

20. "Pontos ricos" se referem a aspectos de difícil compreensão que surgem tanto para o pesquisador como para qualquer pessoa que se defronta com aquilo chamado por Agar (1994) de uma nova "línguacultura" ou mesmo dentro de uma mesma "cultura", neste estudo definida como a comunidade "leve" do aplicativo. 
Excerto da Entrevista 1 com Pedro: "E me chamam de racista"

Luiz Paulo: Vi que vcs preferem certos tipos de homens Pedro: Sim

LP: vc acha q o desejo erótico tem essas predeterminações mesmo? LP: Sim

P: Sexo é Química pura

LP: Não nasce de um papo... de um afeto q surge na conversa?

P: Negros gordos

P: $\operatorname{Sim}$

LP: Ah sei esses não atraem

$P$ : Não temos tesão

LP: E brancos gordos??

P: Já rolou de caras com corpos esculturais. E não bater química. Não rola tbm

LP: Mas rolaria com um negro escultural?

$P:$ Não pq negro não nos atrai : Assim como garotos novinhos

LP: Interessante

P: Pintosas : Afeminados : Cheios de piercing

LP: Mesmo um negro bacana interessante... bonito ...educado

P: Sobrancelhafeita : Nem com um litro de de polo ralfh laurent KKKK

Não temos tesão mesmo

$L P: S e i$

LP: Mas ve entenderia isso como .. só falta de tesão ... ou a falta de ser exposto a homens negros interessantes

$P$ : Como te disse não temos tesão : Já rolou varias vezes mas não deu tesão de repetir e não é nosso prato predileto : Quem gosta de homens bonitos é sao paulo fashion week: Gostamos de maduros putos safados LP: Ah, sei não é uma questão de beleza

$P$ : Não : Negro não rola não temos tesão na cor : Em gordos : Orientais e moleques: Gostamos de caras maduros. Somente

LP: Só fiquei intrigado pq vcs colocam muito explicito q não gostam de negros

P: Questão de gosto : Pior que povo não le

LP: Aparecem negros?

P: Chove

LP: Caramba

$P:$ E me chamam de racistas : Pior e ter que ouvir isso

LP: Não é racismo mesmo então?

$P:$ É questão de gosto 
Minhas duas primeiras perguntas reentextualizam signos que aparecem nos dados do perfil deles que convocam suas performatividades escalares como homens-cis, gays e brancos que são muito específicos sobre as parcerias que procuram (Vi que vcs preferem certos tipos de homens e vc acha q o desejo erótico tem essas predeterminações mes$m o$ ?). Continuo ainda a insistir sobre um modo tão essencializado de definir o desejo da parte dele (Não nasce de um papo... de um afeto $q$ surge na conversa?). Minhas perguntas enunciam, indiretamente, uma solicitação para que se envolva em um movimento de outras projeções escalares sobre quem são ou desejam. Sabendo de meu interesse por estudar performatividades de gênero, sexualidade e raça, Pedro imediatamente usa signos que projetam escalas raciais juntamente com o tamanho do corpo de homens para semiotizar corpos que não os atraem: Negros gordos.

A justaposição dos signos negros e gordos, que indexam discursos de naturezas muito diferentes, é seguida de uma lista de outros signos que continuam a apontar para significados diversos para além das projeções escalares disponibilizadas nos discursos que as categorias do aplicativo indexam (branco gordos, pintosas, afeminados, cheios de piercing, sobrancelhafeita, garotos novinhos, Orientais, e moleques). Essa listagem performatiza Pedro e seu companheiro como homoafetivos na biopolítica do agora (velocidade e produtividade na procura por parceiros). Suas ações refletem a estabilidade dinâmica do aplicativo, forjando escalas sobre os homens em quem estão interessados. Além disso, o apelo que Pedro faz a essa projeção interescalar, que "envolve fazer conexões entre qualidades escalares díspares de modo que uma reforce a outra" (Carr e Fisher, 2016, p. 134), performatiza sua aversão a esses corpos enfaticamente, classificando-os como indesejáveis.

Notam-se ainda quatro traços na produção semiótica da performatividade escalar de Pedro: a) o uso de signos negros e orientais, que igualmente indexam discursos sobre classificações raciais; b) um certo prazer em fazer essa listagem longa para narrar a performatividade escalar do casal, nesse mundo rápido e produtivo de escolhas e de exclusões no mercado de corpos na tela do celular, por assim dizer; c) uma especificação muito clara do que possa ser o desejo sexual, deixando explícito como são especializadíssimos na fabricação semiótico-escalar sobre o que desejam (Não temos tesão mesmo) ao mesmo tempo em 
que sabem a "mercadoria" que procuram, por assim dizer: Quem gosta de homens bonitos é sao paulo fashion week, Gostamos de maduros putos safados; ...não é nosso prato predileto; e Nem com um litro de de polo ralfh laurent $K K K K$; e d) a projeção escalar de quantidade para indicar como seu corpo é muito desejado por negros, colocandose numa posição de relevância na economia do desejo (LP: Aparecem negros? P: Chove)

Todas as minhas tentativas de forjar escalas de maior valor para corpos negros que pudessem ser resemiotizados como de agrado dele (Mas rolaria com um negro escultural?; Mas vc entenderia isso como .. só falta de tesão ... ou a falta de ser exposto a homens negros interessantes?) são "desescalonadas" (Carr e Fischer, 2016, p. 135), fabricando a impossibilidade de tal resemiotização: com Negro não rola não temos tesão na cor e Questão de gosto. Comparado com o próximo entrevistado, Pedro tende a ser monossilábico e reentextualiza textos curtos.

Por fim, cabe mencionar as acusações de racistas e a negações das mesmas (P: E me chamam de racistas :Pior é ter que ouvir isso; LP: Não é racismo mesmo então? P: É questão de gosto). A projeção de escalas de negação de racismo antinegro coocorre com um outro signo (orientais), que igualmente indexa significados sobre uma raça que não os atrai. Da mesma forma, é notável a predicação que semiotiza a raça de um parceiro em potencial como se fosse semelhante a escolher um sorvete ou um carro: Questão de gosto. Além disso, tal semiotização necessita ser compreendida em um país no qual o racismo é estrutural e estruturante das relações entre as pessoas em vários níveis, como já apontado, em que processos históricos moderno-coloniais e de reocidentalização contemporânea coexistem com a modernidade da mobilidade dinâmica, na biopolítica atual.

Ademais, Marlow (2015) argumenta que a negação do racismo invoca a performatividade escalar de superioridade racial do falante em conjunto com a sua negação. É possível dizer que na entrevista essa superioridade pode estar perspectivizada na projeção de desescalonamento de negros e orientais como objetos de desejo, no expertise identificado na mobilização semiótico-escalar do desejo, na quantificação de negros que colocam Pedro como foco de desejo sexual, e 
na negação do racismo. De modo similar, os resultados da pesquisa quantitativista de Callander et al. (2015), na Austrália, indicam que o racismo sexual online da parte de homens brancos gays e bissexuais se correlacionam com atitudes racistas genéricas, desafiando a noção de que a recusa a parceiros identificados com performatividades escalares negras seja simplesmente uma questão de preferência pessoal.

A segunda entrevista é com Leandro, um homem-cis, gay e negro de 30 anos, sobre suas performatividades escalares no aplicativo. Leandro mora na zona norte da cidade, estava de passagem por Copacabana.

Excerto da Entrevista 2 com Leandro: "Mas tu é negão"

LP: Então..vc sofre algum tipo de racismo aqui

L: Sim

LP: Os caras procuram por ve ser negro e tem interesse por isso : Ou ofendem?

L: Tem de tudo! Existem caras que procuram para desfrutarem dos supostos enormes e suculentos paus que negros tem (segundo a fama). Isso em minha opinião é racismo também, pois para relacionamento os negros não servem, mas para foder e ser a virilidade, eles servem! Tem os negros que não gostam de negros. E os casos comuns de racistas assumidos - do tipo: não curto negros - mas que acabam tendo a desculpa de "gosto". Enfim, isso está enraizado na sociedade (mundial)!

LP: Vc acha que é mais um peso ter que enfrentar ainda esse preconceito

L: Claro que é! É um peso (acho que por isso tenho ajuda, sem terapia eu iria surtar). Todos os dias, preciso me impor e enfrentar as pessoas, tendo que me mostrar melhor, pra elas saberem que tenho competência! Se eu fosse Branco, não precisaria desse esforço! É questão dos muitos privilégios que os brancos sempre tiveram, e que historicamente sempre foi da mesma forma! Hj nós (negros) já conseguimos um pequeno espaço, pq pessoas lutaram incansavelmente!

(...)

LP: Vc frequenta algum movimento de consciencia negra?

(...)

LP: Nos movimentos negros eles sabem que vc e gay?

L: Sabem! Mas sempre tem um que quer fazer uma Graça! Dai tenho que dar uns dois berros e tudo fica tranquilo! : Rsrs

LP: Rsss..vejo que vc é bem forte. : Há uma idéia comum de que os movimentos negros não gostam de negros gays 
L: Isso realmente acontece, mas vc precisa se impor! Se não vc fica de fora! L: Sim

LP: Caramba

L: Ouço isso o tempo inteiro

LP: Verdade?

L: "Mas tu é negão"

LP: Caramba.. achava que isso fosse história

L: Ou seja, só Branco pode ser gay?

LP: Exato

LP: Esse negócio de tu é negro e não poder ser gay deve irritar mesmo

L: Irrita muito, eu preciso repetir 10 mil vezes que sou um ser humano como qualquer outro, com as mesmas vontades e com as mesmas capacidades mentais (lógico, alguns desenvolvem mais que outros e de muitas maneiras)!

LP: Sei : Mas vc avalia que o movimento negro foi muito importante para te dar consciência e te dar forca

L: Sim : Não tenho dúvidas disso : Pude me reconhecer como ser humano e participante da sociedade!

Leandro é extremamente bem articulado. Ao contrário de Pedro, Leandro tem o domínio semântico da entrevista: sabe do que está falando e se expressa como alguém que já se envolveu em um grande processo de reflexividade sobre performatividades escalares negras e homoeróticas . Como salientei, Pedro é quase monossilábico.

Leandro começa por confirmar os discursos racistas que enfrenta no aplicativo e os perspectiviza em três classificações. A primeira é marcada pelo signo "fama", que indexicaliza discursos sobre homens brancos que procuram negros com base na ideia de senso comum que identifica esses como possuindo supostos enormes e suculentos paus. Leandro é taxativo ao qualificar tal performatividade escalar como racista: Isso em minha opinião é racismo também, pois para relacionamento os negros não servem, mas para foder e ser a virilidade, eles servem!. Leandro identifica o aplicativo tanto como um lugar para procura de um parceiro para a vida (os homens negros não se qualificam para um relacionamento) como para procura de sexo (os negros para foder e ser a virilidade, (...) servem!). Ele ainda classifica os negros que não gostam de negros: Tem os negros que não gostam de negros. E a terceira categoria que reentextualiza os discursos de negação de racismo da entrevista com Pedro, os quais agora entendo como habitualmente usados no aplicativo: E os casos comuns de racistas assumidos - do tipo: não curto negros - mas que acabam tendo 
a desculpa de "gosto". Essa projeção escalar reentextualiza, portanto, a performatividade escalar que Pedro enfatizou sobre como negros reagem diante de sua negativa. Se, por um lado, a grande reflexividade já apontada anteriormente em relação a Leandro fica clara com essa categorização em três tipos de posicionamentos racistas; por outro, essa reentextualização ecoa a performatividade escalar de Pedro como racista. Leandro termina por qualificar o racismo como constitutivo da estrutura social em todo o mundo : Enfim, isso está enraizado na sociedade (mundial)!. Os textos-respostas de Leandro são "pequenas narrativas" (Georgegakopoulo, 2007) performativas escalares que trazem à tona sua auto-semiotização (Moita-Lopes \& Fabrício, 2018b) e terminam com uma avaliação.

Quando pergunto sobre o peso de ter que enfrentar também racismo no aplicativo, Leandro mobiliza a performatividade escalar de um homem-cis negro que precisa fazer terapia para não surtar porque: [precisa se] impor e enfrentar as pessoas, tendo que [se] mostrar melhor, pra elas saberem que [tem] competência!. Na sequência, faz uma comparação com pessoas brancas: Se eu fosse Branco, não precisaria desse esforço!. Tal comparação é justificada com a recontextualização da Modernidade Colonial: É questão dos muitos privilégios que os brancos sempre tiveram, e que historicamente sempre foi da mesma forma!. Esse texto-resposta de Leandro, como o anterior, tem uma avaliação final. Nesse caso é sobre os pequenos avanços conseguidos pelos negros: $p q$ pessoas lutaram incansavelmente.

Na sequência, pergunto se Leandro frequenta algum movimento de desenvolvimento de consciência negra e se os participantes sabem que ele é gay. Leandro indica ter um grande grau de consciência sobre si próprio. Ele dá prosseguimento a sua performatividade escalar de homem-cis, negro e homoerótico, com a mesma clareza e reflexividade de toda a entrevista. Confirma que sabem e descreve, com humor, como tem que agir quando alguém quer fazer alguma brincadeira com o fato de ele ser gay: Dai tenho que dar uns dois berros e tudo fica tranquilo! : Rsrs. Indo ao encontro dos risos de Leandro, a quem estava no início agradecido pela boa vontade, como a de outros entrevistados, por conversarem comigo, nesse ponto da conversa eu já tinha desenvolvido total simpatia e solidariedade com Leandro. Avalio então a bravura desse jovem homem também com humor (Rsss..vejo que vc é bem 
forte.) e pergunto sobre [a] ideia comum de que os movimentos negros não gostam de negros gays.

Leandro responde positivamente a minha indagação e, mais uma vez, se qualifica como sendo forte: mas vc precisa se impor! Se não vc fica de fora!. Ele dá sequência, mobilizando uma escala temporal para sua performatividade, que enfatiza como cotidianamente é questionado com perguntas que evocam sua posicionalidade como "ativo" no ato sexual: L: Ouço isso o tempo inteiro : Mas tu é negão!. A economia política masculinista, patriarcal e heterocentrada da Modernidade Colonial se faz presente e, como sempre, confunde biologia com desejo sexual. Deixa claro que homens que fazem sexo com homens e são "ativos" não seriam gays: um velho mantra ainda repetido no Brasil em muitos círculos. Esses círculos reentextualizam discursos conflitantes com a biopolitica do agora, como de fato identificado no aplicativo, que ostenta uma variabilidade de desejos para os corpos.

Leandro fecha essa parte da conversa com uma outra avaliação: só Branco pode ser gay e Irrita muito, eu preciso repetir 10 mil vezes que sou um ser humano como qualquer outro, com as mesmas vontades e com as mesmas capacidades mentais. Na sequência, porém, quando peço que ele aquilate o movimento negro, ele perspectiviza com clareza a relevância de tal movimento: Sim : Não tenho dúvidas disso. Pude me reconhecer como ser humano e participante da sociedade!.

A performatividade escalar de Leandro ecoa, por um lado, o que a pesquisa com pessoas negras GBTIQ+ na diáspora caribenha, estadunidense e brasileira tem indicado sobre como esses não são vistos como cidadãos, com direitos plenos, por outros membros da diáspora, inclusive com o apagamento da questão homoerótica no campo de estudos sobre negros nos Estados Unidos (Allen, 2012) e, por outro, a tendência a racializar corpos GBTIQ+ como brancos e sexualizar corpos de cidadãos negros como heterossexuais na África do Sul (Livermon, 2012). Um outro aspecto, porém, é a relevância dos movimentos negros semiotizada por Leandro como muito importante. Tal projeção escalar foi desde o início identificada em como Leandro se situa com segurança, com domínio semântico da conversa e com opiniões bem reflexivas e desenvolvidas ao passo que se envolve em sua performatividade escalar. 


\section{A matriz de inteligibilidade e uma futuridade alternativa}

A "matriz de inteligibilidade" à qual os corpos estão submetidos (Butler, 1990, p. 17), referente a sua dicotomização como masculino e feminino e o correspondente desejo pelo "gênero oposto", pode ser comprendida como incluindo também raça, minimamente, branco e negro, nas entrevistas. Essa matriz, como uma combinação de escalas binarizadas cristalizadas, é a grande projeção escalar que os corpos dos participantes do aplicativo de encontros homoafetivos desafiam, principalmente pela natureza interseccional de como as corporalidades se performatizam nas telas do celular.

As performatividades escalares de gênero, sexualidade e raça semiotizam uma multidão de corpos e desejos, por exemplo, corpos de homens-cis gays, maduros e negros; homens-afeminados, mulatos e jovens; mulheres-trans, louras, quarentonas e dotadas; ou homens-trans, brancos e jovens, em um enorme mosaico de fotografias com perfis. Esses podem ser muito velozmente contatados. É essa mobilidade produtiva que constrói a estabilidade do aplicativo, com cujo ethos os participantes têm que ser socializados para operararem na biopolítca do agora. Essa característica é tornada visível nas reentextualizações de textos e signos conforme a etnografia de tal mobilidade indicou.

No entanto, há dois pontos dessa matriz de inteligibilidade, que corroboram mobilizações escalares da modernidade colonial ou do processo de reocidentalização contemporâneo, sendo também constitutivos da biopolítica do agora. Os dois se referem a como significados cristãos referentes a gênero, sexualidade e raça, categorizados, normalizados e essencializados como 'adequados', 'puros' e 'legítimos', continuam em operação, funcionando na lógica capitalista que a colonização do mundo demandava e a reocidentalização exige.

O primeiro diz respeito a como os corpos dos homens devem ser: uma performatividade escalar que aposta na construção de uma masculinidade hegemônica, heterossexual e patriarcal. Mesmo em um aplicativo de encontros homoafetivos, essa masculinidade transparece na projeção escalar de corpos cis e mesmo trans que se semiotizam por meio de projeção de escalas que emulam tal masculinidade hegemônica, como em perfis emoldurados com os nomes ATIVÃO, DOTADO, 
ATIVO RAIZ, NEGRO22CM etc. Esses signos indexam discursos bem cristalizados sobre como os corpos devem ser.

Da mesma forma, Mas tú é negão aponta para os mesmos tipos de discursos coloniais e heterocentrados sobre os corpos de homens negros. A afirmação Mas tu é negao! opera sob a compreensão de que se um homem negro faz sexo com homens, ele deve ser posicionado como "ativo". Essa é uma compreensão muito tradicional que recupera visões heterocentradas e cristãs, moderno-coloniais, de que o corpo a ser penetrado é semiotizado como o de uma mulher, portanto inferiorizado. O peso que paira sobre os corpos de homens negros e gays em suas performatividades escalares é duplicado, como de fato Leandro ressalta.

Saunders (2020), no entanto, aponta como esses discursos moderno-coloniais heterocentrados estão em contradição com as performatividades escalares de gênero e sexualidade de muitos negros antes de terem sido trazidos para as Américas. Tais performatividades estavam, em muitos casos, bem distantes dos binarismos impostos sobre gênero e sexualidade na Modernidade Colonial, que atuaram sobre os corpos negros, para afirmar a hegemonia política da lógica da conquista. Da mesma forma, Pinho (2018) argumenta como projeções escalares de heterossexualização compulsória para corpos de homens negros continuam em operação no Brasil como efeito da ocidentalização colonial persistente, apesar das muitas contradições encontradas em sua pesquisa, e Oliveira (2018) enfatiza que performatividades escalares homoeróticas para corpos de homens, semiotizados como negros, colocam a própria negritude sob questionamento.

$\mathrm{O}$ segundo ponto se refere ao racismo antinegro indexado pelo signo gosto nas projeções escalares de Pedro, as quais as performatividades de Leandro reentextualizam, por meio da mesma movimentação escalar, i.e. recusar um corpo negro por não ter 'gosto sexual' por ele. Leandro reentextualiza o mesmo signo de Pedro - gosto -, o que é indicativo da existência de uma ordem indexical, compartilhada pelos participantes do aplicativo. A projeção escalar de Pedro encontra ressonância nos discursos moderno-coloniais racistas sobre a inferioridade dos corpos negros que atravessou séculos. Leandro, porém, historiciza os entrocamentos discurivos da escravidão que continuam a dar privilégios aos brancos. 
Nesse sentido, é crítico o momento histórico contemporâneo em várias partes do mundo, caracterizado por posições políticas da extrema direita fascista, que tem ocupado mais e mais espaço na cena política internacional e advogado explicitamente o uso de ferramentas digitais para destruir ideais progressistas por meio de fake-news, memes absurdos e trollagem, inclusive sobre nossas performatividades escalares.

Tais ferramentais digitais são cada vez mais exploradas no nosso mundo da estabilidade dinâmica ao passo que transparecem uma tentativa ameaçadora de reocidentalização do mundo, na construção de uma tanatopolítica. Como discutido no livro, editado por Sedgwick (2019), por meio da organização de movimentos supremacistas brancos, a extrema direita têm chegado ao ponto de pensar uma projeção escalar espacial para o globo - um etnoespaço - para ser ocupado somente por corpos brancos. Do mesmo modo, há lideranças explicitamente misóginas, que priorizam performatividades do gênero masculino em relação às de raça e etnia assim como discursos homofóbicos, que prestigiam um mundo heterocentrado. Está aí a reocidentalização em operação. É esse mundo que Mbembe (2020: s/p) qualifica como orientado por "um imaginário fascista" que "requer a eliminação de certos tipos de humanos e de modos de vida".

Em um tal contexto sociohistórico, entendo a posição de descrença total quanto à possibilidade de mudanças sociais estruturais, tanto do que tem sido formulado como "Negatividade Queer"21 por teóricos queer (Marti, 2017) assim como "Afropessimismo"22 (Wilderson, 2020) por teóricos de estudos raciais, uma vez que não veem nenhum futuro para os corpos que desafiam as matrizes da inteligibilidade heterossexual e branca. Essas formulações decretam a morte social desses corpos. Insisto, contudo, que devemos ter esperança política na construção de uma futuridade alternativa que continue a desestabilizar as estruturas de opressão.

Tal alternativa requer clareza crítica, porém, em relação à biopolítica do agora. Os avanços conseguidos até o presente pelos movimentos

21. Negatividade queer se funda na ideia de que vidas LGBTIQ+ são impossíveis por que estão sendo cooptadas pela ótica mercantilista que normaliza o "desvio" assim como por que estão, em geral, fora do ciclo da reprodução humana. 
sociais são ubíquos e, por isso mesmo, provocaram a volta de uma direita fascista reativa. Entendo, porém, que desses ganhos contra a opressão, conseguidos ao longo da história pelos movimentos sociais, não se pode recuar. Não há volta ao passado mesmo por que "os futuros estão muito mais próximos de nós do que qualquer passado aos quais [forças fascistas] queira[m] retornar ou revisitar" (Puar, 2007: xix). É necessário continuar radicalizando na luta por transformações sociopolíticas de liberdade e mais democracia.

Nessa direção, ressalto o trabalho teórico-programático sobre a construção de um populismo de esquerda em Mouffe (2018). A autora descreve uma tal prática como um modo de organizar o futuro, na promoção de alianças entre aqueles que sofrem: pobres, negros, homossexuais, mulheres, imigrantes etc. em suas interseccionalidades. Se fazer pesquisa é um modo de construir um discurso sobre a vida social (Santos, 2001), entendo o trabalho de Mouffe (2018) como um bom começo para refletir sobre uma nova futuridade.

\section{Referências}

AGAMBEN, Giorgio. 2002[1995]. Homo sacer. O poder soberano e a vida nua. Trad. Henrique Burigo. Belo Horizonte: Editora UFMG.

AGAMBEN, Giorgio. 2014[2006]. O amigo \& O que é um dispositivo? Chapecó: Argos.

AGAR, Michael H. 1994. Language shock: Understanding the culture of conversation. New York: William Morrow.

AGHA, Asif. 2007. Language and social relations. Cambridge: Cambridge University Press.

ALMEIDA, Silvio Luiz. 2019. Racismo Estrutural. São Paulo: Pólen.

ALLEN, Jafari S. 2012. Black/Queer/Diaspora at the Current Conjuncture. Journal of Lesbian and Gay Studies, 18: 2-3.

AUSTIN, John L. 1962. How to do things with words. Oxford: Claredon Press.

BARNARD, Ian. 2004. Queer race. Nova York: Lang.

BERNARDINO-COSTA, Joaze; GROSFOGUEL, Ramón. 2016. Decolonialidade e perspectiva negra. Soc. Estado, 31: 1, pp. 15-24.

BLOMMAERT, Jan. 2005. Discourse: key topics in sociolinguistics. Cambridge: Cambridge University Press. 
BLOMMAERT, Jan. 2007. Grassroots literacy. Writing, identity and voice in Central Africa. University of Jyväskyla and Tilburg Unversity. Working papers in language and diversity, paper 2.

BLOMMAERT, Jan. 2010. The sociolinguistics of globalization. Cambridge: Cambridge University Press.

BLOMMAERT, Jan; RAMPTON, Ben. 2012. Language and superdiversity: a position paper. Working papers in urban language \& literacies, Paper 70. Tilburg University and King's College.

BLOMMAERT, Jan; DE FINA, Anna. 2015. Chronotopic identities: On the timespace organization of who we are. Tilburg papers in Cultures Studies, paper 153. Tilburg University.

BLOMMAERT, Jan; VARIS, Piia. 2015. Enoughness, accent and light communities: Essays on contemporary identities. Tilburg papers in Culture Studies, paper 139. Tilburg University.

BONFANTE, Gleiton M. 2016. Erótica dos signos em aplicativos de pegação. Rio de Janeiro: Editora Multifoco.

BROWN, Wendy. 2016. In the account of neoliberalism. European Graduate School Video Lectures. Disponível em: https://www. youtube.com/watch?v=tqQ_dIjr3uU. Acesso em 10/8/2020.

BROWN, Wendy. 2019. In the ruins of neoliberalism. Palestra apresentada na Social Science Matrix "Authors Meet Critics" Departments of African American Studies and Sociology at UC Berkeley. Esse evento foi gravado no dia 5/12/2019, 2019. Disponível em: https://www. youtube.com/watch?v=0EHVTznPXOE. Acesso em 14/8/2020.

BUTLER, Judith. 1990. Gender trouble: feminism and the subversion of identity. Nova York: Routledge.

CAMARGO, Mábia. 2019. “Acuenda esse bajubá!': indexicalidades e interseccionalidades nas performances narrativas de uma travesti quilombola. Tese de Doutorado. Programa Interdisciplinar de Linguística Aplicada. Universidade Federal do Rio de Janeiro.

CALLANDER, Denton; NEWMAN, Christy; HOLT, Martin. 2015. Is sexual racism really racism? Distinguishing atitudes toward sexual racism and generic racism among gay and bissexual men. Arch Sex Beaviour, doi 10.10007/s10508-015-0587-3.

CARR, E. Summerson; FISHER, Brooke. 2016. Interscaling awe, deescalating disaster. In: Carr, E. Summerson; Lempert, Michael (Eds.). Scale: discourse and dimensions of social life, pp. 133-156. Oakland: University of California Press.

CARR, E. Summerson; LEMPERT, Michael. (Eds.). 2016. Scale. Discourse and dimensions of social life. Oakland: University of California Press. 
COLLINS, Jim. [2011]2020. Indexicalidades de línguas em contato em tempos de globalização: diálogos com o legado de John Gumperz. In: FABRÍCIO, Branca F. (Ed.). Sociolinguística interacional. Perspectivas inspiradoras e dedobramentos contemporâneos, pp. 263-294. Rio de Janeiro: Morula Editorial.

CRENSHAW, Kimberle. 1989. Demarginalizing the intersection of race and sex: A black feminist critique of antidiscrimination doctrine, feminist theory and antiracist politics, University of Chicago Legal Forum: 1, Artigo 8. Disponível em: http://chicagounbound.uchicago. edu/uclf/vol1989/iss1/8.

DELEUZE, Gilles. 1992[1990]. Conversações. Trad Peter Pál Pelbart. São Paulo: Editora 34.

DERRIDA, Jacques. 1988[1972]. Limited Inc. Trad. Samuel Weber e Jeffrey Mehlman. Evanston: Northwestern University Press.

FABRÍCIO, Branca F. 2018. Policing the borderland in a digital lusophone territory: the pragmatics of entextualization. In: MOITA LOPES, Luiz Paulo (Ed.). Global Portuguese. Linguistic ideologies in late modernity, pp. 66-86. Nova York: Routledge.

FABRICIO, Branca F.; MOITA LOPES, Luiz Paulo. 2019. Creating queer moments at a Brazilian school by forging innovative sociolinguistic scalar perspectives in classrooms. In: KJARAN, Jón; SAUNTSON, Helen. (Eds.). Schools as queer transformative spaces: global narratives on gender and sexualities in schools, pp. 40-55. Londres: Routledge.

FOUCAULT, Michel. 1987[1975]. Vigiar e punir: o nascimento da prisão. Trad. Raquel Ramalhete. Petrópolis: Vozes.

FOUCAULT, Michel. 1999[1997]. Em defesa da sociedade. Trad. Maria Ermantina Galvão. São Paulo: Martins Fontes.

FOUCAULT, Michel. 1983[1972]. Preface. Deleuze, Gilles e Guattari, Félix. Anti-Edipus. Capitalism and schrizophrenia. Trad. Robert Hurley, Mark Seen e Helen R. Lane, pp. xi - xiv. Minneapolis: University of Minnesota Press.

GALLO, Sílvio D. 2016. Biopolítica e educação: novos dispositivos de subjetivação. Palestra. V Colóquio Latino-Americano de Biopolítica. Instituto Humanitas, UNISINOS. Youtube.

GAUDIO, Rudolf P. 2001. White men do it too: racialized (homo)sexualities in postcolonial Hausland. Journal of Linguistic Anthropology, 11(1): pp. 36-51.

GEORGEGAKOPOULO, Alexandra. 2007. Small stories, interaction and identities. Amsterdam: John Benjamins. 
HALL, Stuart. 2003. Quando foi o pós-colonial? Pensando no limite. In: HALL, Stuart. Da diáspora: identidades e mediações culturais, pp. 101-131. Belo Horizonte: Editora UFMG.

HINE, Christine. 2015. Ethnography for the internet: embedded, embodied and everyday. Londres: Bloomsbury Academic.

JACQUEMET, Marco. 2005. Transidiomatic practices: language and power in the age of globalization. Language \& Communication 25, pp. 257-277.

JAGOSE, AnneMarie. 1996. Queer Theory. An Introduction. Nova York: New York University Press.

KOZINETS, Robert V. 2010. Netnography. Doing ethnographic research online. Londres: Sage.

GUIMARÃES, Thayse Figueira. 2014. Embates entre performances corpóreo-discursivas em trajetórias textuas: uma etnografia multisituada. Tese de Doutorado. Programa Interdisciplinar de Linguística Aplicada. Universidade Federal do Rio de Janeiro.

HELLER, Monica. 2010. Language as a resource in the globalized new economy. In: Coupland, N. (Ed.). The handbook of language and globalization, pp. 349-365. Nova York: Wiley-Blackwell.

LIVERMON, Xavier. 2012. Queer(y)ing freedom: black queer visibilities in postapartheid South Africa. Journal of Lesbian and Gay Studies, 18 (2-3): pp. 297-323.

MALY, Ico. 2018. Algorithmic populism and algorithmic activism. 12 Minutes to Read an Article. Disponível em: https://www. researchgate.net/publication/332495674_Algorithmic_populism_ and_algorithmic_activism_12_minutes_to_read.

MARLOW, Mikaela L. 2015. The American Dream? Anti-immigrant discourse bubbling up from the Coca-Cola 'It's Beautiful' advertisement. Discourse and Communication. 9: 6, pp. 625-641.

MARTINS, Eduardo E. B. 2020. Prazeres plásticos: dispositivos do saberpoder na atual economia de plataforma. Tese de Doutorado. Programa Interdisciplinar de Linguística Aplicada. Universidade Federal do Rio de Janeiro.

MBEMBE, Achile. 2014[2013]. Crítica da razão negra. Trad. Marta Lança. Lisboa: Antígona.

MBEMBE, Achile. 2020. The politics of the future world: reflections on racism in the planetary age. Palestra ministrada no webseminar do Departamento de Religião, Rice University. Houston, Estados Unidos, 10/9/2020.

MIGNOLO, Walter. 2007[2005]. La idea de América Latina. La herida colonial y la opción decolonial. Barcelona: Gedisa Editorial. 
MIGNOLO, Walter. 2005. Raça origina conflito andino, diz estudioso, Entrevista de Walter Mignolo à Cláudia Antunes. Disponível em: https://www1.folha.uol.com.br/fsp/mundo/ft1906200510.htm. Acesso em 21/8/2020.

MIGNOLO, Walter. 2020. Conversa com Walter Mignolo. Associação de Linguística Aplicada do Brasil (ALAB), transmitido em 5 de agosto de 2020, you tube da ALAB.

MOITA LOPES, Luiz Paulo. 1998. Discursos de identidade em sala de aula de leitura de L1: a construção da diferença. In: SIGNORINI, Inês (Ed.). Lingua(gem) e identidade: elementos para uma discussão no campo aplicado, pp. 303-330. Campinas: Mercado de Letras.

MOITA LOPES, Luiz Paulo. 2002. Identidades fragmentadas: A construção discursiva de raça, gênero e sexualidade em sala de aula. Campinas: Mercado de Letras.

MOITA LOPES, Luiz Paulo. 2006. On being white, heterosexual and male in a Brazilian school: multiple positionings in oral narratives. In: DE FINA, Anna; SCHIFFRIN, Deborah; BAMBERG, Michael (Eds.). Discourse and identity, pp. 288-313. Cambridge: Cambridge University Press.

MOITA LOPES, Luiz Paulo (org.). 2018. Global Portuguese. Linguistic ideologies in late modernity. Nova York: Routledge.

MOITA LOPES, Luiz Paulo. 2017. Guarani/Portuguese/Castellano rap on the borderland: transidiomaticity, indexicalities and text spetacularity. In: CAVALCANTI, Marilda; MAHER, Terezinha (Eds.). Multilingual Brazil: language resources, identities and ideologies in a globalized world, pp.178-190. Nova York: Routledge.

MOITA LOPES, Luiz Paulo; FABRÍCIO, Branca F. 2018a. 'Does the picture below show a heterosexual couple or not?': reflexivity, entextualization, scales and intersectionalities in a gay man's blog. In: M. Cooke \& J. Gray (Eds.). Special Issue of Gender and Language: Intersectionality, language and queer lives, 12(4):457-478.

MOITA LOPES, Luiz Paulo; FABRÍCIO, Branca F. 2018b. Viagem textual pelo sul global: ideologias linguísticas queer e metapragmáticas translocais. Linguagem em (Dis)curso - LemD. Tubarão, SC, 18: 3, pp. 759-784.

MOITA LOPES, Luiz Paulo; FABRÍCIO, Branca F, GUIMARÃES, Thayse F. 2019. Scaling queer performativities of genders and sexualities in the periphery of Rio de Janeiro in digital and face-toface semiotic encounters. In: Sjaak, Kroon; Jos Swanenberg (Eds.). Language and Culture on the Margins. Local/Global Interactions, pp. 127-144. Londres: Routledge. 
MOITA LOPES, Luiz Paulo. 2020. Presidente ou presidenta? Ideologia linguística e embates metapragmáticos. In: SILVA, Wagner R. (Ed.). Contribuições sociais da Linguística Aplicada (no prelo).

MOUFFE, Chantal. 2018. For a left populism. Londres: Verso.

NAKASSIS, Constantine V. 2016. Scaling red and the horror of trademark. In: CARR, E. Summerson; LEMPERT, Michael (Eds.). Scale: discourse and dimensions of social life. pp. 159-184. Oakland: University of California Press.

OLIVEIRA, Megg Rayara G. 2018. Seguindo os passos 'delicados' de gays afeminados, viados e bichas pretas no Brasil. In: CAETANO, Marcio; SILVA JUNIOR, Paulo Melgaço (Eds.). De guri a cabra macho. Masculinidades no Brasil, pp. 127-145. Rio de Janeiro: Lamparina.

PELUCIO, Larissa. 2015. Narrativas infiéis: notas metodológicas e afetivas sobre experiências das masculinidades em um site de encontros para pessoas casadas. Cadernos Pagu, 1: pp. 31-60.

PENNYCOOK, Alastair. 2012. Language and mobility. Unexpected places. Bristol: Multilingual Matters.

PINHO, Osmundo. 2018. Sacrifício de Orfeu: masculinidades negras no contexto da antinegritude em Salvador. In Caetano, Marcio; Silva Junior, Paulo Melgaço (Eds.) De guri a cabra macho. Masculinidades no Brasil, pp. 146-173. Rio de Janeiro: Lamparina.

PINTO, Joana Plaza. 2018. From prefigured speaker identities to the disinvention of Portuguese. In: MOITA LOPES, Luiz Paulo (org.). Global Portuguese. Linguistic ideologies in late modernity, pp. 6686. Nova York: Routledge.

PUAR, Jasbir K. 2007. Terrorist assemblages. Homonationalism in queer times. Durham: Duke University Press.

PRECIADO, Paul B. 2015. Cambiar de Voz. Catalunya trans. El Estado mental. Disponível em: https://elestadomental.com/especiales/ cambiar-de-voz/catalunya-trans.

ROSA, Hartmut. 2019[2005]. Aceleração. A transformação das estruturas temporais na Modernidade. Trad. Rafael H. Silveira. São Paulo: Editora Unesp.

RUTI, Mari. 2017. The ethics of opting out. Queer theory's defiant subjects. Nova York: Columbia University Press.

SANDEL, Todd. 2015. Rich Points. The international encyclopedia of language and social interaction. New York: John Wiley \& Sons, Inc. DOI: 10.1002/9781118611463/wbielsi67.

SANTOS, Boaventura de S. 2001. Pela mão de Alice. O social e o político na pós-modernidade. São Paulo: Cortez. 
SAUNDERS, Tanya. 2020. Epistemologias do corpo negro-feminino. Mesa-redonda de encerramento do Congresso Internacional Yorubanto, 27 de junho de 2020. Youtube.

SEDGEWICK, Eve K. 1990. The epistemology of the closet. Berkeley: University of California Press.

SEDGWICK, Mark (Ed.). 2019. Key thinkers of the radical right. Behind the new threat to liberal democracy. Oxford: Oxford University Press.

SILVERSTEIN, Michael. 2003. Indexical order and the dialectics of sociolinguistic life. Language and Communication, 23: pp. 193229.

SULLIVAN, Nikki. 2003. A critical introduction to queer theory. New York: New York University Press.

SCHULTZ, Victor B. 2020. “Aqui o menino usa saia mesmo?”: fricções escalares em trajetórias textuais de um documento escolar. Tese de Doutorado. Programa Interdisciplinar de Pós-graduação em Linguística Aplicada. UFRJ.

TUFECKI, Zeinep. 2015. Algorithmic harms beyond Facebook and google: emergent challenges of computational agency. COLO. TECH. LJ. 13: pp. 203-217.

VENN, Couze. 2000. Occidentalism: Modernity and subjectivity. Londres: Sage.

VERTOVEC, Steven. 2007. Super-diversity and its implications. Ethnic and racial studies, 30: 6, pp. 1004-1054.

WILDERSON, Frank B. 2020. Afropessimism. Nova York: Liveright Publishing Corporation.

WITTGENSTEIN, Ludiwig. 1968[1953]. Philosophical investigations. Trad. G. E. M. Anscombe. Nova York: The Macmillan Company.

Recebido em: 10/08/2020

Aprovado em: 15/09/2020 